\title{
Etiopathogenic aspects upon distal tibia articular fractures
}

${ }^{1}$ Clinic of Orthopedics and Traumatology, Emergency County Hospital Constanța, Romania

\begin{abstract}
The paper propose a complex annalysis regarding etiopathogenic approach of the tibial pilon. The study was made upon the articular fractures of distal tibia, hospitalised and treated in Orthopaedic-Traumatology Clinic of Constanta Emergency Clinical Hospital, between 2007-2011, and consist of 245 patients. The lesional graduality will be found in the anathomoclinical forms of the fractures. The grade of soft tissue devitalisation will influence the local evolution and will promote the appearance and extension of skin necrosis in case of ireversible ischemia. In case of direct trauma, but with low energy or in case of indirect trauma, perifracture lesions are restrained and evolution can be favourable to cicatrization. The correct dyagnosis of these fractures are a mandatory stage of the presurgical planning and was made by annalysing the x-rays made in 2 incidencies, in emergency, and which were repeated when it was needed.

The lesional graduality of bone and soft tissue structures is direct proportional with the type of traumatic mechanism and with the level of energy which produced the fracture. The traumatic mechanism can produce lesional characteristics, by direct mechanism (work accidents, falling from high or same level) or by indirect mechanism with forces transmitted through
\end{abstract}

Obada Bogdan

Clinic of Orthopedics and Traumatology

Emergency County Hospital

Constanța, Romania

email: bogdanobada@yahoo.com talus (forced inversion/eversion).

The fracture type must be evaluated upon the clinical and prognostical criteria of $\mathrm{AO}$ and Ruedi-Allgower classification, which suggest the therapeutical manners too. The evaluation of soft tissues is made by the Gustilo-Anderson classification, the only one which can establish correctly the graduality and the severity of lesions.

Keywords: tibial pilon fracture, etiopathogeny, dyagnosis

\section{Introduction}

The tibial pilon fractures has very often an unfavourable evolution, which explain the frequency of complications dominated by the healing of tegument problems and consolidation disorders. The soft tissues have a high risk of ischemic problems, especially on internal side, where the skin is soft, very few mobile and bad vascularity. The absence of tibial muscle insertions explain why the periostal vascularity is poor.

The cutaneous problems and those related to osteosynthesis explain the dificulties of a precise therapeutic standardisation and impose prudence and rigurosity in choosing the therapeutic method $[1,2,3]$

The paper propose a complex annalysis regarding etiopathogenic approach of the tibial pilon. 
Material. Methods.

The study was made upon the articular fractures of distal tibia, hospitalised and treated in Orthopaedic-Traumatology Clinic of Constanta Emergency Clinical Hospital, between 2007-2011, and consist of 245 patients.

Inclusion criteria:

- articular distal tibia fractures

exclusion criteria:

- non-articular distal tibia fractures

- malleolar tibial fractures

\section{Results}

The patient goup we studied consist of 245 patients, 186 men (76\%) and 59 women (24\%), treated between 2007-2011 in our Clinic. The mean age was 44.2 years (17-81 years), fractures produced in the following circumstances: car accidents, falling from high, falling from same level, sport accidents and other causes.

According Ruedi si Allgower classification were: $33.46 \%$ type 1 I, $32.65 \%$ type II, $33.89 \%$ type III. 61 fractures were open.

184 cases $(75 \%)$ were closed fractures, 61 cases $(25 \%)$ were primary open fractures, 67 cases $(27.34 \%)$ were fractures with limited cutaneous disorders (phlictena, superficial skin necrosis, traumatic oedema and microcirculatory damage compartmental sindrom-like) and 33 (13.46\%) fractures were secondary open.

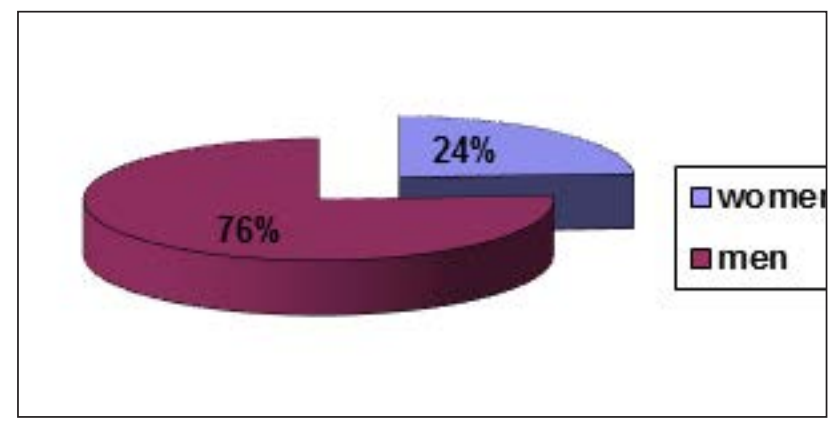

Figure 1 Sex incidence

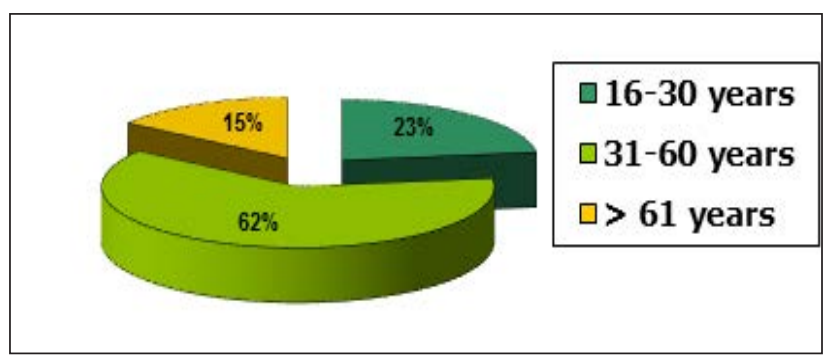

Figure 2 Age groups

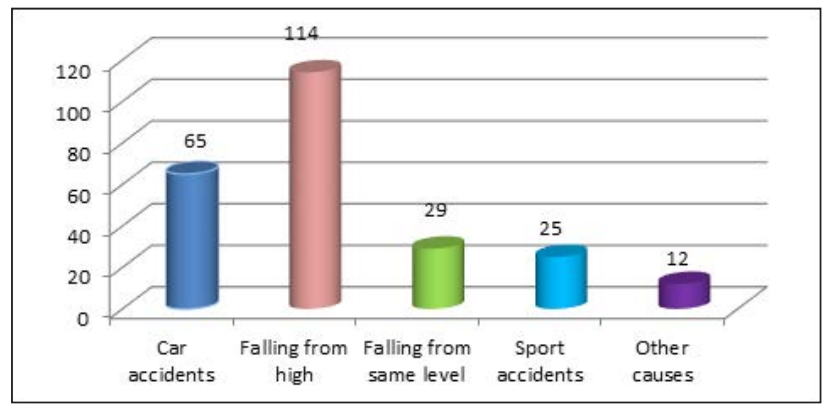

Figure 3 Ethiology

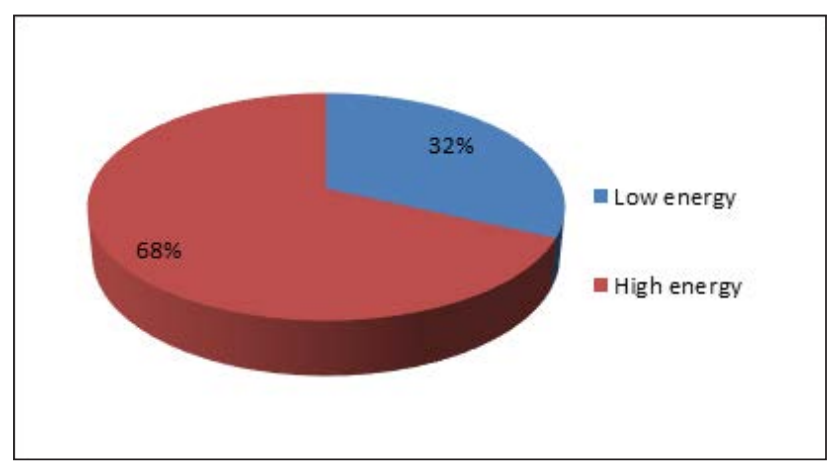

Figure 4 Traumatic energy 
Table I Soft tissue aspect

\begin{tabular}{|l|l|l|l|}
\hline $\begin{array}{l}\text { Primary } \\
\text { open } \\
\text { fractures }\end{array}$ & $\begin{array}{l}\text { Secondary } \\
\text { open } \\
\text { fractures }\end{array}$ & $\begin{array}{l}\text { Closed } \\
\text { fractures }\end{array}$ & $\begin{array}{l}\text { Fractures } \\
\text { with limited } \\
\text { cutaneous } \\
\text { disorders }\end{array}$ \\
\hline 61 & 33 & 84 & 67 \\
\hline
\end{tabular}

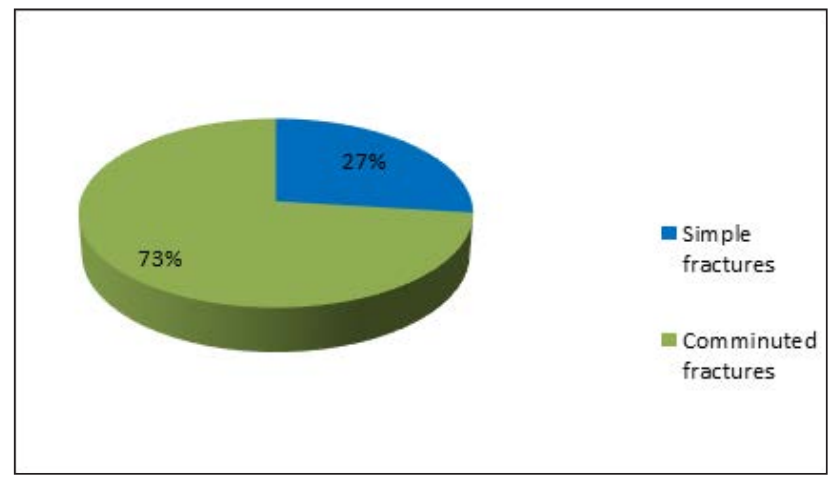

Figure 5 Fracture type

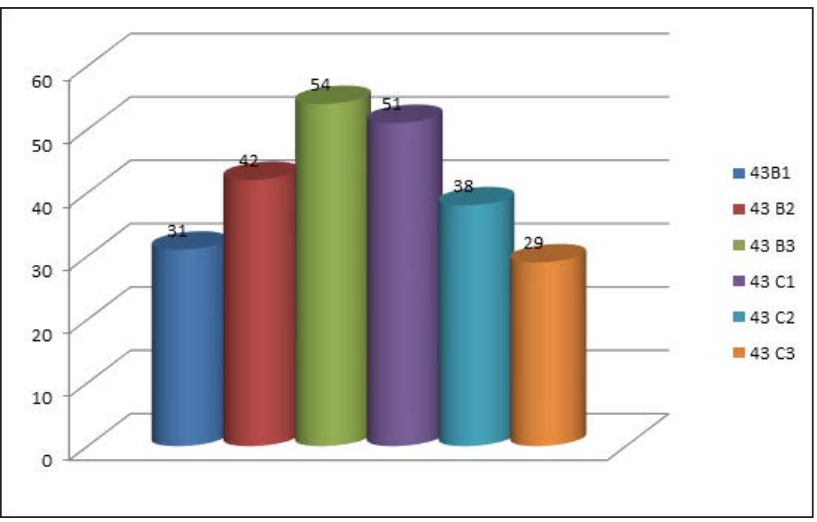

Figure 6 AO clasification

Table II Ruedi and Allgower classification with correspondence to $A O$

\begin{tabular}{|c|c|c|c|c|}
\hline $\begin{array}{l}\text { Ruedi şi } \\
\text { Allgower } \\
\text { classification }\end{array}$ & \multicolumn{2}{|c|}{ AO classification } & No & $\%$ \\
\hline \multirow[t]{2}{*}{ Type I } & B1 & 31 & \multirow{2}{*}{82} & \multirow{2}{*}{33.46} \\
\hline & $\mathrm{C} 1$ & 51 & & \\
\hline \multirow[t]{2}{*}{ Type II } & B2 & 42 & \multirow{2}{*}{80} & \multirow{2}{*}{32.65} \\
\hline & $\mathrm{C} 2$ & 38 & & \\
\hline \multirow[t]{2}{*}{ Type III } & B3 & 54 & \multirow{2}{*}{83} & \multirow{2}{*}{33.89} \\
\hline & $\mathrm{C} 3$ & 29 & & \\
\hline
\end{tabular}

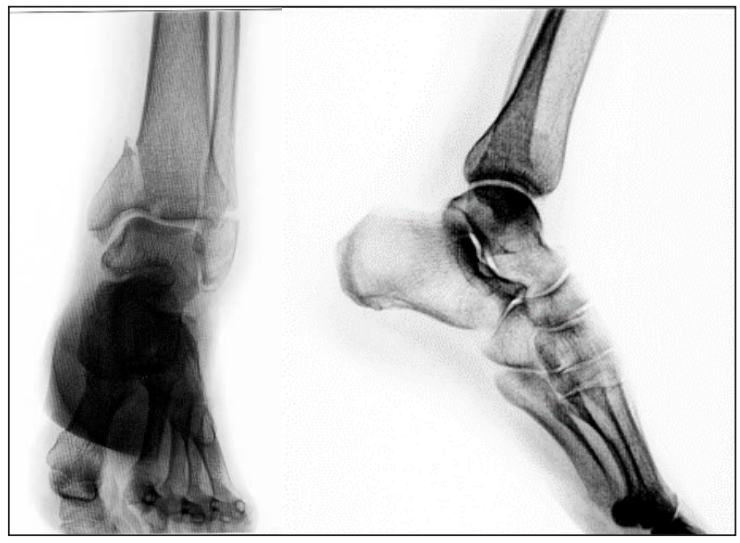

Figure 7 43-B1

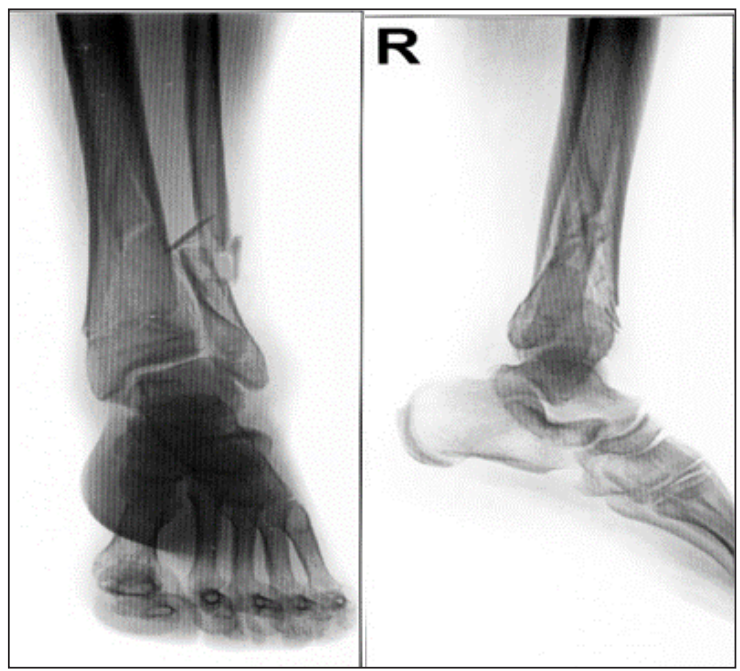

Figure 8 43-B2

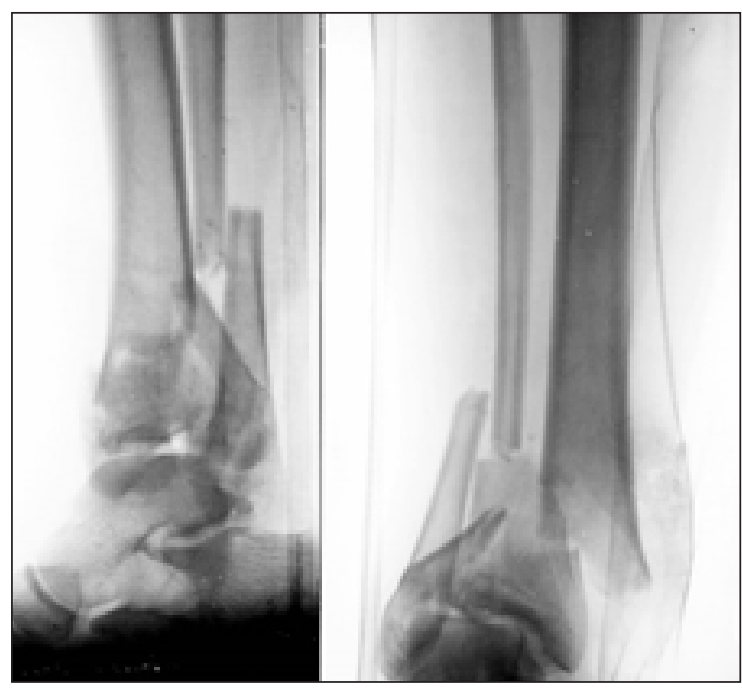

Figure 9 43-B3 


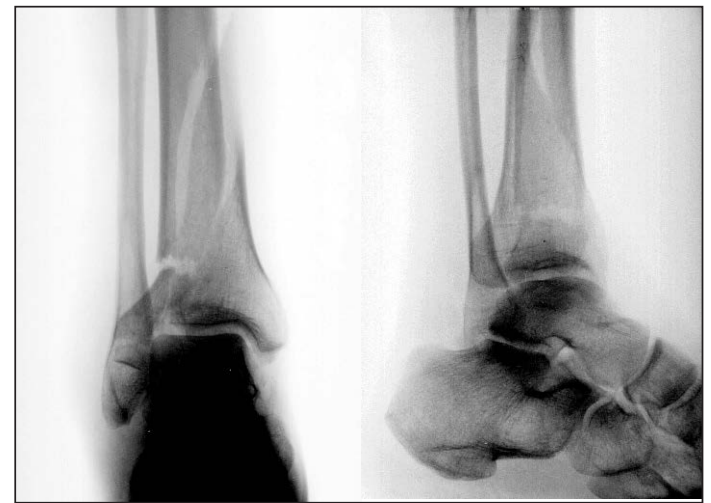

Figure 10 43-C1

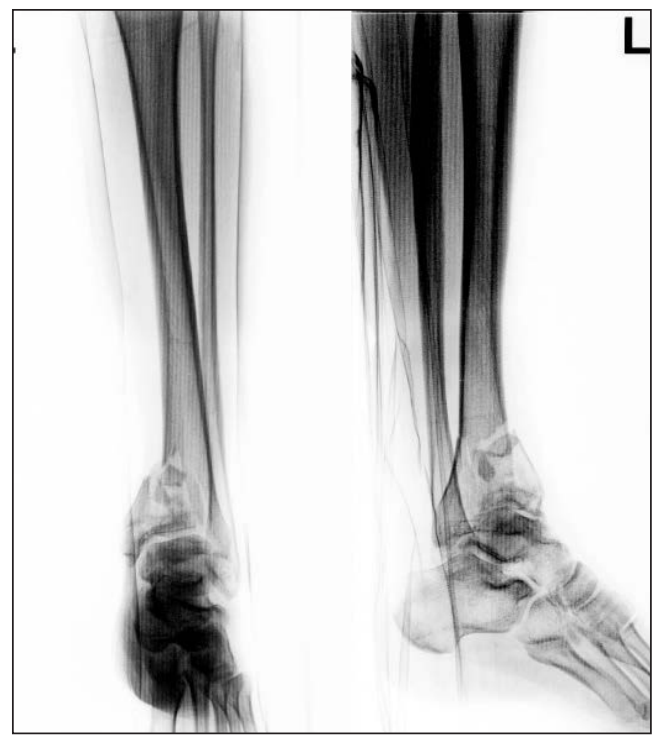

Figure 11 43-C2

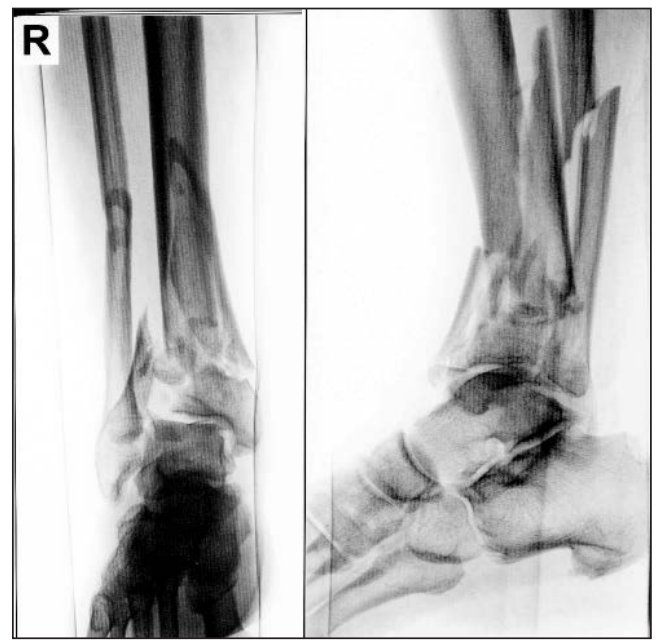

Figure 12 43-C3
Table III Fractures association

\begin{tabular}{|l|c|}
\hline Fractures association & Cases \\
\hline pilon + peroneal malleolus & 96 \\
\hline $\begin{array}{l}\text { pilon + tibial malleolus + posterior } \\
\text { foot luxation }\end{array}$ & 65 \\
\hline $\begin{array}{l}\text { pilon + tibial malleolus + external } \\
\text { foot luxation }\end{array}$ & 42 \\
\hline pilon + peroneus & 61 \\
\hline pilon + tibial malleolus & 139 \\
\hline pilon with no other association & 88 \\
\hline pilon + tibial dyaphisis extension & 43 \\
\hline
\end{tabular}

\section{Discussions}

Etiology was dominated by the falling from high, from which 97 were work accidents and 17 suicidal tempations, followed by the car traffic accidents in 65 cases. The most common squeletal associated lession was peroneal fracture (39\%).

High frequency of tibial pilon fractures met to men, 186 patients $(75.91 \%)$ can be explained by the traumatic circumstances characteristical to males (work with increased traumatic risk, acr accidents, alcohol consumption).

The highest frequency was at the group age of $31-60$ years $(62 \%)$, followed by the age between $16-30$ years $(23 \%)$ and the age over 61 years $(15 \%)$.

An important factor which can be favourable for the evolution of open fractures for the groups age under 51 years can be the capacity of tissue regeneration, a good biological status which can influence favourable for healing, in comparison elderly patients with possible associated disease, which can badly influence the evolution. The individual reactivity, from local microcirculatory point of view, can influence the evolution of lessions, being differencies between young and old patients. $[4,5]$

The lesional graduality will be found in the anathomo-clinical forms of the fractures. The grade of soft tissue devitalisation will influence the local evolution and will promote the appearance and 
extension of skin necrosis in case of ireversible ischemia. In case of direct trauma, but with low energy or in case of indirect trauma, perifracture lesions are restrained and evolution can be favourable to cicatrization. $[6,7]$

We found that cominuted fractures had the highest frequency, 179 patients $(73 \%)$, comparison with simple fractures, 66 caes $(27 \%)$, being a relation between the intensity of trauma and the type of solft tissue lesion. The fracture characteristics as grade of comminution and type of the opening can characterise indirectly the force of traumatic energy.

According AO classification were fractures 43 B1 12.65\%, 43 B2 17.14\%, 43 B3 22\%, 43 C1 20.8\%, 43 C2 15.51\% și 43 C3 11.84\%. According RuediAllgower classification were $33.46 \%$ fractures type I, $32.65 \%$ fractures type II and $33.89 \%$ fractures type III. There is an anathomo-pathological correspondence between the 2 classifications as type I Ruedi Allgower with $\mathrm{B} 1$ and $\mathrm{C} 1 \mathrm{AO}$, type II with $\mathrm{B} 2$ and $\mathrm{C} 2$ and type III with $\mathrm{B} 3$ and $\mathrm{C} 3$, correspondency which increase as grade for every type of fracture in same time with increasing of fracture complexity.

The most frequent association was between tibial pilon fracture and pure tibial malleolus fracture in 139 cases, fact explained by the complexity of the mechanism which produced the fracture and the high force of traumatic energy. In many cases, the fracture line is complex and involve the entire articular surface of the pilon, with detaching of the tibial malleolus. In 88 cases were tibial pilon fractures with no other association and in 96 cases the tibial pilon fracture were associated with peroneal malleolus fracture.

The soft tissue quality was evaluated using Gustilo-Anderson classification. In our group we remarked a high frequency of closed fractures in 84 cases, followed by primary open fractures 61 caeses, secondary open fractures 33 cases and fractures with limited skin disorders 67 cases.

According Gustilo-Anderson classification were 19 open fractures type I, 17 open fractures type II, 14 open fractures type IIIA, 9 open fractures type IIIB and 2 open fractures type IIIC.

The correct dyagnosis of these fractures are a mandatory stage of the presurgical planning and was made by annalysing the $\mathrm{x}$-rays made in 2 incidencies, in emergency, and which were repeated when it was needed.

\section{Conclusions}

The anathomic characteristics of talo-crural joint impose the tibial pilon fractures typical lesional characteristics, multiple clinical aspects, therapeutical dificulties and sometimes an unclear pronosis. The biomechanical characteristics of tibial pilon impose anathomical reconstruction as perfect and stable as possible is, following the remake of the biomechanical axis and the articular congruency.

The lesional graduality of bone and soft tissue structures is direct proportional with the type of traumatic mechanism and with the level of energy which produced the fracture. The traumatic mechanism can produce lesional characteristics, by direct mechanism (work accidents, falling from high or same level) or by indirect mechanism with forces transmitted through talus (forced inversion/eversion).

The fracture characteristics are the consequences of intensity and the way was applied the traumatic mechanism. It is necesary the correct evaluation of the lesional graduality, at hospitalisation, in emergency and in the next days, mandatory to formulate a proper therapeutical strategy.

The fracture type must be evaluated upon the clinical and prognostical criteria of AO and Ruedi-Allgower classification, which suggest the therapeutical manners too. The evaluation of soft tissues is made by the Gustilo-Anderson classification, the only one which can establish correctly the graduality and the severity of lesions.

\section{References}

1. Bartolozzi, P. \& Lavini, F. (2004). Fractures of the Tibial Pilon. Milano, Italia: Springer-Verlag

2. Obadă, N. \& Obadă, B. (2001). Sindroamele 
de compartiment posttraumatice ale gambei. Constanta: Ed. Muntenia\&Leda

3. Ruedi, T.P. \& Allgower, M. (1979). The operative treatment of intraarticular fractures of the lower end of the tibia, Clinical Orthopedics and Related Research.(138), 105-110

4. Ovadia, D.N. \& Beals, R.K. (1986). Fractures of the tibial plafond. J Bone Joint Surg Am, 68(4), 543-551.

5. Olerud, C. \& Molander, H. (1984). A scoring scale for symptom evaluation after ankle fracture. Arch Orthop Trauma Surg, 103(3), 190-194.

6. Ruedi, T.P. \& Murphy, W.L. (2000). $A O$ principles of fracture management. Thieme

7. Bour, P., Aubry, P. \& Fieve, G. (1992). Vascularisation du pilon tibial: applications thèrapeutiques. $66^{\circ}$ Réunion annuelle de la SOFCOT Les fractures récentes du pilon tibial de 1'adulte. Rev Chir Orthop. 78[Suppl 1], 47-48 